\section{The healing journey: incorporating psychological and spiritual dimensions into the care of cancer patients}

A.J. Cunningham oc PhD C Psych

\section{KEY WORDS}

Mind, body, spirit, research, healing, suffering, stress, coping, psychological

\section{URL: http://www.current-oncology.com/ index.php/oncology/article/view/269/252}

\section{E-JOURNAL LINKED ABSTRACT}

Research on the factors that promote healing of the body through mind and spirit is at a very early stage. Reliance on experimental designs seems premature; we need much more exploratory research to identify relevant variables and useful therapeutic approaches before applying to them the same methods used to evaluate drugs. The Healing Journey is a program that has been in operation since 1982 at the Princess Margaret Hospital, Toronto, Ontario. Observational data collection, followed by qualitative analysis has demonstrated benefits for many cancer patients.

\section{Supporting cancer patients through the continuum of care: a view from the age of social networks and computer- mediated communication}

J.L. Bender Bsc Msc,* L. O’Grady $\mathrm{PhD}{ }^{\dagger}{ }^{\dagger}$ and A.R. Jadad MD DPhil ${ }^{\ddagger}$

\section{KEY WORDS}

Social support, supportive care, computer-mediated communication, social networks, Internet

\section{URL: http://www.current-oncology.com/ index.php/oncology/article/view/270/236}

\section{E-JOURNAL LINKED ABSTRACT}

Almost since its inception, the Internet has been used by ordinary people to connect with peers and to exchange health-related information and support. With the rapid development of software applications deliberately designed to facilitate social interaction, a new era is dawning in which patients and their loved ones can collaboratively build knowledge related to coping with illness, while meeting their mutual supportive care needs in a timely way, regardless of location. In this article, we provide background information on the use of "one-to-one” (for example, e-mail), "one-to-many" (for example, e-mail lists), and "many-to-many” (for example, message boards and chat rooms, and more recently, applications associated with Web 2.0) computer-mediated communication to nurture health-related social networks and online supportive care. We also discuss research that has investigated the use of social networks by patients, highlight opportunities for health professionals in this area, and describe new advances that are fuelling this new era of collaboration in the management of cancer.

\section{The Soul's Wisdom: Stories of Living and Dying}

M.L.S. Vachon RN PhD. Departments of Psychiatry and Public Health Sciences, University of Toronto, Toronto, Ontario, Canada.

\section{KEY WORDS}

Spirituality

\section{URL: http://www.current-oncology.com/ index.php/oncology/article/view/272/237}

\section{E-JOURNAL LINKED ABSTRACT}

Cancer can lead to spiritual transformation, which can be seen as a form of alchemy. During this process, patients, family members, and even professional caregivers can find themselves having spiritual experiences that go beyond any they had previously encountered. This paper provides qualitative descriptions of the "Field" or "Soul Wisdom" experienced by patients and caregivers.

\section{Research and Regulatory Issues for Integrative Oncology}

S.M. Sagar MD and R.K.W. Wong MB Bs. McMaster University and the Juravinski Cancer Centre, Hamilton, Ontario, Canada.

\section{KEY WORDS}

Integrative oncology, CAM, research, regulation, acupuncture, natural health products, herbs

*With the increasing national and international popularity and exposure of Current Oncology, the queue of excellent submissions continues to lengthen. After substantial consideration, the journal's management has determined that the best way to manage this abundance is to move to a "hybrid" of combined print and electronic publication, with every e-manuscript being supported by a full print abstract and key words, and of course, indexing in PubMed for international recognition. 
URL: http://www.current-oncology.com/ index.php/oncology/article/view/273/242

\section{E-JOURNAL LINKED ABSTRACT}

Many oncology patients are empowering themselves to self-treat with herbs, nutritional supplements, and mind-body techniques. Other practitioners, such as acupuncturists, are becoming involved in the supportive care of cancer patients. Government research agencies are supporting studies that evaluate complementary therapies. This educational article provides an overview of the challenges in designing appropriate studies of complementary and alternative therapies, evaluating the results, and regulating implementation of useful therapies.

\section{An Integrated Support and Information Centre in a Large U.K. Cancer Centre Established in 1993 and Replicated in More Than 60 Units Across the United Kingdom and Australia}

E.J. Maher. Mount Vernon Cancer Centre, Northwood, Middlesex, U.K.

\section{KEY WORDS}

Cancer support, Macmillan, CAM, complementary, patient-centered, survivorship

\section{URL: http://www.current-oncology.com/ index.php/oncology/article/view/275/282}

\section{E-JOURNAL LINKED ABSTRACT}

Established in 1993 after a 2-year consultation between professionals and cancer patients, the Lynda Jackson Macmillan Centre (LJMC) has been a catalyst for change in the United Kingdom. The Centre began with a small core staff in a purpose-built building next to a cancer centre, networking with outreach workers in 12 surrounding hospitals, with a mission to improve information, communication, and support for cancer patients. Since 1996, the LJMC model has been adopted and developed by the charity Macmillan Cancer Support and has been spread to more than 60 units across the United Kingdom and Australia.

Introducing complementary therapies (CAMs) to a cancer centre was a particular early challenge. Establishing a shared understanding of the role of complementary therapies and developing nationally accredited written information about them, credible recruitment and governance procedures for therapy practitioners, agreed outcome measures, and peer-reviewed evaluation and research have all been important in engaging cancer physicians and managers; however, charitable funding is still required to support free access to most complementary therapies.

An integrated supportive care service for cancer patients begins with a shift in the culture of cancer treatment organizations, moving from a professional-centred to a patient-centred agenda. Real reach and impact requires "new" ideas and services to be integrated into the routine practice of the cancer care delivery organizations. A key lesson learned over the last 15 years is that an integrated support centre must continually adapt to be viable. Sustaining meaningful user guidance is a particular challenge. Support for self-management and the testing and development of CAM services are growing parts of the portfolio.

\section{Integrative Cancer Care in a US Academic Cancer Centre: The Memorial Sloan-Kettering Experience}

G. Deng MD PhD. Memorial Sloan-Kettering Cancer Center, New York, NY, U.S.A.

\section{KEY WORDS}

Integrative medicine, complementary and alternative medicine, cancer, oncology

\section{URL: http://www.current-oncology.com/ index.php/oncology/article/view/276/238}

\section{E-JOURNAL LINKED ABSTRACT}

Various surveys show that interest in complementary and alternative medicine (CAM) is high among cancer patients. Patients want to explore all options that may help their treatment. Many CAм modalities offer patients an active role in their self-care, and the resulting sense of empowerment is very appealing. On the other hand, many unscrupulous marketeers promote alternative cancer "cures," targeting cancer patients who are particularly vulnerable. Some alternative therapies can hurt patients by delaying effective treatment or by causing adverse effects or detrimental interactions with other medications. It is not in the best interest of cancer patients if they cannot get appropriate guidance on the use of САм from the health care professionals who are part of their cancer care team.

The Integrative Medicine Service at Memorial Sloan-Kettering Cancer Center in New York was established in 1999 to address patient interest in CAM, to incorporate helpful complementary therapies into each patient's overall treatment management, to guide patients in avoiding harmful alternative therapies, and to develop prospective research to evaluate the efficacy of CAM modalities. 


\section{Impact and Outcomes of an Iyengar Yoga Program in a Cancer Centre}

M.D. Duncan MSc, A. Leis PhD, and J.W. TaylorBrown MSW RSw. Department of Community Health and Epidemiology, University of Saskatchewan, Saskatoon, Saskatchewan, and Department of Patient and Family Support Services, CancerCare Manitoba, Winnipeg, Manitoba, Canada.

\section{KEY WORDS}

Iyengar yoga, cancer, complementary and alternative medicine, integrative oncology, mixed methodology

\section{URL: http://www.current-oncology.com/ index.php/oncology/article/view/284/280}

\section{E-JOURNAL LINKED ABSTRACT}

Background: Individuals have increasingly sought complementary therapies to enhance health and wellbeing during cancer, although little evidence of their effect is available.

Objectives: We investigated

- $\quad$ how an Iyengar yoga program affects the self-identified worst symptom in a group of participants.

- $\quad$ whether quality of life, spiritual well-being, and mood disturbance change over the Iyengar yoga program and at 6 weeks after the program.

- $\quad$ how, from a participant's perspective, the Iyengar yoga program complements conventional cancer treatment.

Patients and Methods: This pre-post instrumental collective case study used a mixed methods design and was conducted at a private Iyengar yoga studio. The sample consisted of 24 volunteers (23 women, 1 man; 88\% Caucasian; mean age: 49 years) who were currently on treatment or who had been treated for cancer within the previous 6 months, and who participated in ten 90-minute weekly Iyengar yoga classes.

The main outcome measures were most-bothersome symptom (Measure Your Medical Outcome Profile 2 instrument), quality of life and spiritual well-being (Functional Assessment of Chronic Illness Therapy-General subscale and Spiritual subscale), and mood disturbance (Profile of Mood States-Short Form). Participant perspectives were obtained in qualitative interviews.

Results: Statistically significant improvements were reported in most-bothersome symptom $\left(t_{(23)}=5.242\right.$; $p<0.001)$, quality of life $\left(F_{(2,46)}=14.5 ; p<0.001\right)$, spiritual well-being $\left(F_{(2,46)}=14.4 ; p<0.001\right)$, and mood disturbance $\left(F_{(2,46)}=10.8 ; p<0.001\right)$ during the program. At follow-up, quality of life $\left(t_{(21)}=-3.7 ; p=\right.$ $0.001)$ and mood disturbance $\left(t_{(21)}=2.4 ; p=0.025\right)$ significantly improved over time. Categorical aggregation of the interview data showed that participants felt the program provided them with various benefits not included on the outcomes questionnaires.

Conclusions: Over the course of the Iyengar Yoga for Cancer program, participants reported an improvement in overall well-being. The program was also found to present participants with a holistic approach to care and to provide tools to effectively manage the demands of living with cancer and its treatment.

\section{How to Put Wellness on the Prescription Pad: Recommendations}

P.R. Fortin MD. Toronto Western Hospital, Toronto, Ontario, Canada.

\section{KEY WORDS}

Integrative oncology, holistic cancer treatment

\section{URL: http://www.current-oncology.com/ index.php/oncology/article/view/277/239}

\section{E-JOURNAL LINKED ABSTRACT}

The Integrating Wellness into Cancer Care conference was held at the University of Toronto, October 4-5, 2007, and was dedicated to the memory of the late Dr. Véronique Benk.This article summarizes the workshops at that conference.

The notion of wellness and an integrated approach should be introduced from the outset as part of the cancer patient's management. Having wellness as part of the treatment sets a standard for taking care of the patient's emotional, spiritual, physical, and nutritional needs, and for providing information on complementary therapies. A focus on holistic supportive care during treatment and survivorship is important.

The whole medical team should support an integrative program. Referral to an education program and one-to-one assessments by a point person such as an advanced nurse practitioner, a social worker, or a psychological counsellor with appropriate special training should be mandatory. The concept of a pathfinder or cancer guide was discussed.

Interactions of natural health products with biomedical cancer treatments D. Seely ND MSC* and D. Oneschuk $\mathrm{MD}^{\dagger}$

\section{KEY WORDS}

Complementary medicine, CAM, natural health products, NHPS, chemotherapy, radiotherapy, antioxidants, drug-herb interactions, pharmacology 
URL: http://www.current-oncology.com/ index.php/oncology/article/view/282/247

\section{E-JOURNAL LINKED ABSTRACT}

The use of complementary and alternative medicine (CAM), including the ingestion of natural health products (NHPS), is common among cancer patients. Of concern to clinicians and patients alike is the possibility that CAM, used concurrently with biomedical therapy, may interact poorly with that therapy, especially chemotherapy and radiotherapy. Proponents of NHPs argue that taking such products can help to reduce the side effects of conventional therapy and can provide an additional anticancer effect. However, opponents insist that the potential for harm is too great to warrant the risk of concurrent administration. There are promising examples of specific NHPs that may provide patient benefit even when given in close proximity both to chemotherapy and to radiotherapy, but unfortunately, in part because of a rather limited evidence base, caution is warranted when considering the issue of therapeutic interactions. Strategic application of NHPs before or after conventional therapy may be considered; however, concurrent application should be avoided as a general principle until further evidence is available regarding specific interactions.

\section{Integrative practices of Canadian oncol- ogy health professionals}

A.S.A. Brazier $\mathrm{PhD},{ }^{*} \dagger$ L.G. Balneaves $\mathrm{PhD},{ }^{*}, \dagger \mathrm{D}$. Seely ND Msc, ${ }^{\ddagger}$ J.E. Stephen phD, ${ }^{\S}$ N. Suryaprakash $\mathrm{PhD},^{\dagger}$ and J.W. Taylor-Brown MSW Rswll

\section{KEY WORDS}

Oncology health professionals, integrative cancer care, qualitative research, complementary therapies

\section{URL: http://www.current-oncology.com/} index.php/oncology/article/view/283/253

\section{E-JOURNAL LINKED ABSTRACT}

Objective: Cancer patients are increasingly known to use complementary medicine (CAM) during conventional treatment, but data are limited on how Canadian oncology health professionals attempt to assist patients with their use of CAM in the context of conventional cancer care. As part of a larger qualitative study assessing the perceptions of Canadian oncology health professionals regarding integrated breast cancer care, we undertook an exploration of current integrative practices of oncology health professionals.

Design: Using an interpretive description research design and a purposive sampling, we conducted a series of in-depth qualitative interviews with various oncology health professionals recruited from provincial cancer agencies, hospitals, integrative clinics, and private practice settings in four Canadian cities: Vancouver, Winnipeg, Montreal, and Halifax. A total of 16 oncology health professionals participated, including medical and radiation oncologists, nurses, and pharmacists.

Results: Findings highlighted two main strategies used by oncology health professionals to create a more integrative approach for cancer patients:

- $\quad$ acting as an integrative care guide, and

- collaborating with other health professionals.

Conclusions: Although few clear standards of practice or guidance material were in place within their organizational settings, health professionals discussed some integrative roles that they had adopted, depending on interest, knowledge, and skills, in supporting patients with CAM decisions. Given that cancer patients report that they want to be able to confer with their conventional health professionals, particularly their oncologists, about their CAM use, health professionals who elect to adopt integrative practices are likely offering patients much-welcomed support. 